\title{
A neural field model of decision making in the posterior parietal cortex
}

\author{
Christian Klaes ${ }^{1,2}$, Sebastian Schneegans ${ }^{3}$, Gregor Schöner ${ }^{3}$, Alexander Gail ${ }^{1,2^{*}}$ \\ From Twentieth Annual Computational Neuroscience Meeting: CNS*2011 \\ Stockholm, Sweden. 23-28 July 2011
}

The process of decision making often involves incomplete information about the outcome of the decision. In order to plan goal-directed reaching, it is necessary to combine sensory information about goal positions with information about the current behavioral context to select an appropriate action. A central role in this process is attributed to the posterior parietal cortex (PPC), which has been associated with value based selection of action and perceptual decision making. As an underlying mechanism, it has been proposed that the selection and specification of possible actions are not two distinct, sequential operations, but that instead the decision for an action emerges from the competition between different movement plans [1].

Here, we present a neural field model [2] to describe the dynamics of action selection in the PPC, developed in parallel with an electrophysiological study in monkeys [3]. The task required rule-based spatial remapping of a motor goal, which was indicated by a spatial cue, depending on a contextual cue. The model can learn the context-dependent remapping task via an implemented Hebbian-style learning rule. It is trained from a prestructured initial state (with default cue-response mapping behavior), using a training procedure that emulates the training procedure of the monkeys. The trained model developed activity patterns and neuronal tunings consistent with the empirical data. We then examined how actions are planned in the absence of an explicit rule, i.e. with no contextual cue. In this case the model showed a decision bias towards one goal (Fig. 1A) or an equal representation of both potential goals (Fig. 1B), depending on the input statistics during training. The

\footnotetext{
* Correspondence: agail@gwdg.de

'Sensorimotor group, German Primate Center - Leibniz Institute for Primate Research, Göttingen, 37077, Germany

Full list of author information is available at the end of the article
}

model remained susceptible to later experience and changes of the reward schedule.

This matches the observations in monkeys performing the same task and it provides an account for the

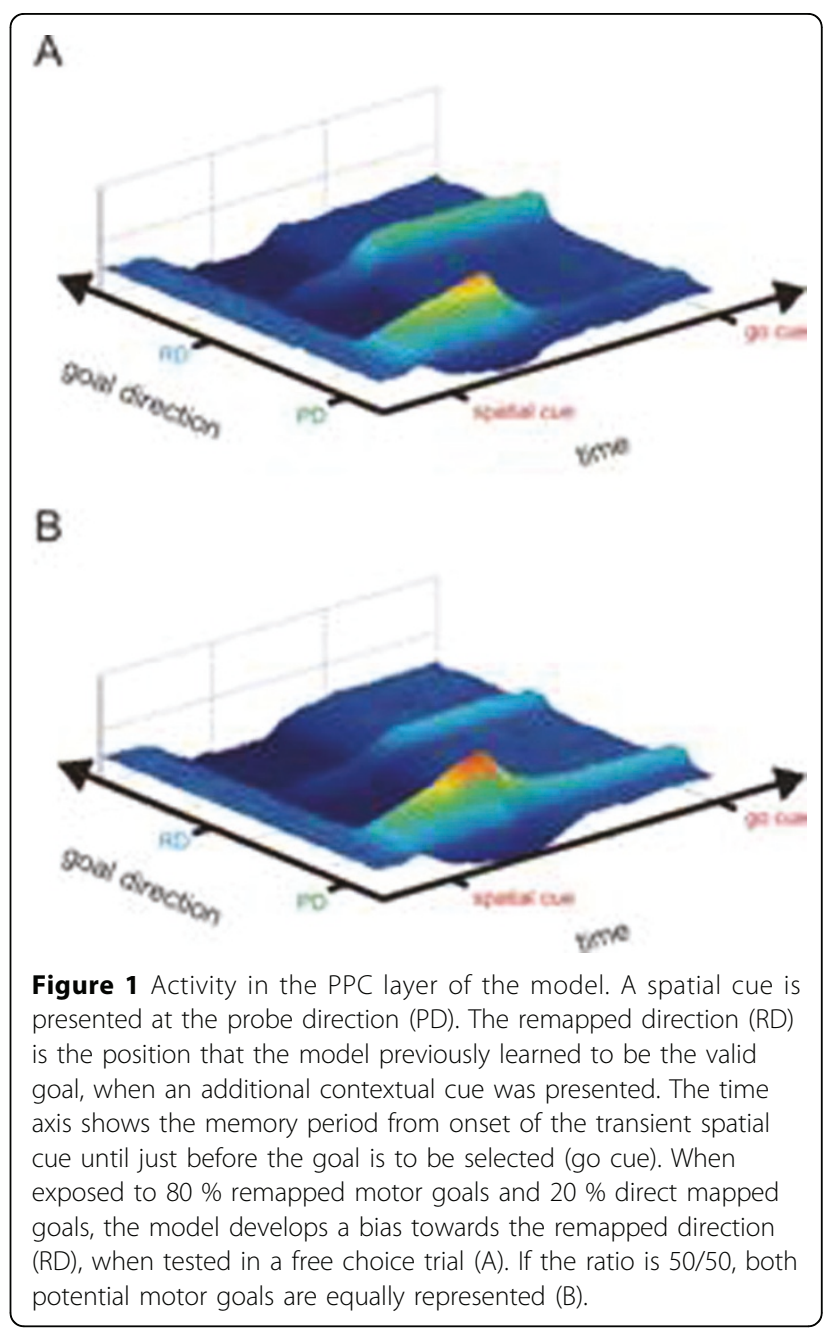

C Biomed Central

() 2011 Klaes et al; licensee BioMed Central Ltd. This is an open access article distributed under the terms of the Creative Commons Attribution License (http://creativecommons.org/licenses/by/2.0), which permits unrestricted use, distribution, and reproduction in any medium, provided the original work is properly cited. 
formation of action plans under ambiguous conditions. The field model provides an integrated account for the operations of sensorimotor transformations, working memory, and action selection required for decision making.

\section{Author details}

${ }^{1}$ Sensorimotor group, German Primate Center - Leibniz Institute for Primate Research, Göttingen, 37077, Germany. ${ }^{2}$ Bernstein Center for Computational Neuroscience, Göttingen, Germany. ${ }^{3}$ Institute for Neural Computation, Ruhr University Bochum, Bochum, 44780, Germany.

Published: 18 July 2011

\section{References}

1. Cisek P: Cortical mechanisms of action selection: the affordance competition hypothesis. Philosophical Trans R Soc Lond B Biol Sci 2007, 362:1585-1599.

2. Erlhagen W, Schöner G: Dynamic field theory of movement preparation. Psychol Rev 2002, 109:545-572.

3. Klaes C, Westendorff S, Chakrabarti S, Gail A: Choosing goals, not rules: Deciding among rule-based action plans. Neuron 2011.

\section{Submit your next manuscript to BioMed Central} and take full advantage of:

- Convenient online submission

- Thorough peer review

- No space constraints or color figure charges

- Immediate publication on acceptance

- Inclusion in PubMed, CAS, Scopus and Google Scholar

- Research which is freely available for redistribution

Submit your manuscript at www.biomedcentral.com/submit 